\title{
FOTOGRAMETRIA E A RELAÇÃO COM DIFERENTES MEDIDAS DA ESCOLIOSE IDIOPÁTICA
}

Lisiane Yuri Sako, Carolina Orsi, Dalva Minonroze Albuquerque Ferreira, Célia Aparecida Stellutti Pachioni.

Curso de Fisioterapia - UNESP, Campus de Presidente Prudente. E-mail: lisi.sk@hotmail.com, PIBIC.

\section{RESUMO}

A escoliose é uma alteração tridimensional das vértebras, caracterizada por curvatura lateral da coluna vertebral com extensão, inclinação lateral e rotação das vértebras. $O$ desequilíbrio postural é fator preocupante pela possibilidade de adaptação do corpo a deformidades permanentes. 0 objetivo foi avaliar a postura em portadores de escoliose idiopática, através da mensuração das gibosidades, mensuração da profundidade das lordoses e mensuração da flexibilidade relacionando-as por meio da fotogrametria. Participaram do estudo 11 mulheres de 18 a 25 anos. As curvaturas vertebrais e as gibosidades, foram mensuradas por meio de uma régua adaptada a nível d'água. A flexibilidade foi avaliada pelo Banco de Wells e o teste de inclinação lateral. A fotogrametria foi feita pela analise das imagens digitalizadas por meio do Software Corporis Pro. Foram detectadas alterações posturais nos indivíduos com escoliose através de métodos não invasivos e seguros. Quando correlacionados com fotogrametria, não apresentaram diferenças significativas.

Palavras-chave: escoliose, postura, fotogrametria.

\section{INTRODUÇÃO}

A escoliose é uma alteração tridimensional das vértebras, caracterizada por uma curvatura lateral da coluna vertebral com extensão, inclinação lateral e rotação das vértebras da região acometida (Santos et al., 2012). O desequilíbrio postural é objeto de preocupação tanto do paciente quanto do fisioterapeuta, não devido ao aspecto estético do desvio, mas também pela possibilidade de adaptação do corpo a deformidades permanentes, causando, em muitos casos dor e restrição da mobilidade (Pereira, 2003). Em um alinhamento postural ideal, espera-se que os músculos, articulações e suas estruturas se encontrem em estado de equilíbrio dinâmico, gerando uma quantidade mínima de esforço e sobrecarga, conduzindo a uma eficiência ótima para o aparelho locomotor. Porém, apesar de haver esse consenso em relação à boa postura e suas implicações, a postura corporal é um fenômeno complexo e de difícil mensuração (Souza et al, 2011). A avaliação da postura corporal na posição ortostática tem sido amplamente utilizada há várias décadas, tanto na pratica clinica quanto na pesquisa, como um instrumento de diagnóstico, de planejamento e de acompanhamento do tratamento fisioterapêutico. De maneira geral, estudos relatam diversos métodos de análise biomecânica da postura em posição estática, entre estes, a fotogrametria digital (Souza et al, 2011). 


\section{OBJETIVOS}

Avaliar a postura em portadores de escoliose idiopática, por meio de teste de Adams, mensuração das curvas da coluna vertebral no plano sagital (lordoses), mensuração da flexibilidade relacionando-as com fotogrametria.

\section{METODOLOGIA}

Ensaio clínico, desenvolvido no Laboratório de Estudos Clínicos em Fisioterapia (LECFisio) da Faculdade de Ciências e Tecnologia (FCT) - Universidade Estadual Paulista (UNESP), Campus de Presidente Prudente aprovado pelo Comitê de Ética em Pesquisa da FCT/UNESP (CAAE: 025460012.6.0000.5402). Participou da pesquisa 11 sujeitos, com idade entre $15-25$ anos e todos participantes do estudo receberam esclarecimentos sobre os objetivos e procedimentos do mesmo, assinando o "Termo de Consentimento Livre e Esclarecido".

Para mensuração da gibosidade foi realizado o teste de Adams (Goldberg et al, 2001) ou da protusão da musculatura toraco lombar. Além disso, foi utilizado um instrumento de madeira para a avaliação da gibosidade torácica e lombar de acordo com o protocolo de (Ferreira; Defino, 2001; Ferreira et al., 2009; Ferreira et al., 2010a; Salate; Aroni; Ferreira, 2003; Surós, 1977).

Para a mensuração das lordoses no plano sagital, utilizamos na posição ortostática, uma régua adaptada a um nível d'água. (Ferreira et al., 2010b). Foram mensurados quatro pontos: Medida I - Lordose cervical cefálica; Medida II - Lordose lombar cefálica; Medida III - Lordose cervical caudal e Medida IV - Lordose lombar caudal.

Para a realização do teste de flexibilidade, foi utilizado um banco de Wells (marca Sanny, capacidade de zero a $68 \mathrm{~cm}$.), estabilizado contra uma parede. (Faria Jr, Barros, 1998) e o teste de inclinação lateral do tronco para mensurar a distância do dedo médio deslizando sobre a coxa durante a inclinação lateral da coluna vertebral em ambos os lados (Danielsson et al., 2006).

Para a fotogrametria, o protocolo realizado constou de quatro vistas fotográficas diferentes: vista frontal anterior, vista frontal posterior, vista lateral direita e vista lateral esquerda. Para análise das fotos utilizou-se o Software Corporis Pro e foram selecionados os seguintes pontos anatômicos: tragus da orelha, acrômio, espinha ilíaca antero superior (EIAS), trocânter maior do fêmur, linha articular do joelho e maléolo lateral, ângulo inferior da escápula, epicôndilo lateral, espinha ilíaca postero superior (EIPS) e processo espinhoso da sétima cervical.

Para as fotos em vista anterior e posterior quanto mais distante o valor de 0 , , maior será o desnivelamento entre dois pontos anatômicos bilaterais e o eixo horizontal. Na vista lateral, foram 
analisadas a posição pélvica (anteversão/retroversão) através das EIAS, trocanter maior e o ponto médio da interlinha articular do joelho na face lateral, sendo a linha articular o vértice do ângulo. Caracterizou-se que, quanto maior a medida angular, maior a anteversão da pelve. A lordose cervical também foi avaliada através do ângulo formado a partir do trágus da orelha, C7 e acrômio, sendo o acrômio o vértice do ângulo. Quanto maior a medida angular, maior anteriorização da cabeça e menor a lordose cervical.

A análise estatística utilizada foi a correlação de Spearman, a qual analisa a ordenação dos sujeitos dentro do grupo. O software utilizado foi o BioEstat (versão 5.0) e adotou-se um p-valor inferior a 5\%. Foram correlacionados os seguintes dados: gibosidades torácica, tóraco-lombar e lombar com a fotogrametria; lordose cervical e lombar cefálica com a fotogrametria; lordose cervical e lombar caudal com a fotogrametria; flexibilidade com a fotogrametria e teste de inclinação lateral com a fotogrametria.

\section{RESULTADOS}

As alterações posturais que apresentaram correlação significativa foram: relação positiva entre gibosidade lombar e desnivelamento na vista posterior do ombro ( $r=0.72, p$-valor=0,011); relação positiva entre gibosidade lombar e desnivelamento na vista posterior dos epicôndilos laterais $(r=0.72, p$-valor $=0,011)$; relação negativa entre gibosidade torácica e posição pélvica $(r=-$ 0.68, p-valor $=0,011)$; relação positiva entre gibosidade lombar e desnivelamento na vista posterior do ombro $(r=0.75, p$-valor=0,011); relação positiva entre lordose cervical cefálica e desnivelamento posterior do ângulo inferior da escápula ( $r=0.71 ; p$-valor=0,011); relação positiva entre lordose cervical caudal e desnivelamento posterior do ângulo inferior da escápula ( $r=0.67$; $p$-valor= 0,011); relação positiva entre flexibilidade e desnivelamento anterior do fêmur $(r=0.65$; $p$-valor= 0,011); relação negativa entre inclinação lateral direita com desnivelamento de tragus ( $r=$ - 0.82; p-valor=0,011); relação negativa entre inclinação lateral esquerda e ângulo da lordose cervical ( $r=-0.67, p$-valor $=0,011)$ e relação negativa entre inclinação lateral esquerda e desnivelamento das espinhas ilíacas póstero-superiores ( $r=-0.70, p$-valor $=0,011)$. Os dados evidenciaram que não houve correlação significativa para a maioria das variáveis das alterações posturais. 


\section{DISCUSSÃO}

A escoliose é uma deformidade tridimensional que modifica toda a biomecânica funcional e geometria postural, e são cada vez mais importantes estudos tridimensionais sobre o tema. Isso tem levado os pesquisadores a desenvolverem um número maior de estudos sobre métodos de mensuração, na tentativa de analisar não somente o plano frontal, mas também o plano axial e principalmente o plano sagital (Carnielli et al, 2009). Apesar do instrumento utilizado no presente estudo, que apenas permitiu uma caracterização bidimensional dos aspectos posturais, mostrou ser um instrumento confiável para verificar os principais desnivelamentos em indivíduos com escoliose.

De acordo com as mensurações da gibosidade relacionadas à fotogrametria, as análises deste estudo apontaram apenas que quanto maior a gibosidade na região torácica, menor a alteração pélvica e quanto maior a gibosidade na região lombar, maior o desnivelamento de ombros na vista anterior e posterior e em epicôndilos laterais. As medidas de gibosidade através de réguas não apresentaram boa correlação com as medidas da fotogrametria. Dentro da literatura, não houve estudos que corroborassem com nossos achados, porém intercalar medidas não-invasivas entre medidas radiológicas é fundamental para se obter um bom parâmetro quantitativo de acompanhamento das escolioses sem expor os pacientes aos riscos decorrentes da radiação excessiva (FERREIRA; DEFINO, 2001).

Em nosso estudo, a flexibilidade foi correlacionada com as imagens obtidas pela fotogrametria e os dados evidenciaram que não houve correlação significativa para a maioria das variáveis das alterações posturais. O único dado significativo mostrou que quanto maior a flexibilidade, maior o desnivelamento no fêmur. Gurney, 2001demonstrou-se que relativamente discrepâncias na perna menor pode levar a um grande aumento na atividade muscular de vários grupos musculares, o que torna impossível manter uma posição de repouso completo em pé. Além disso, uma maior quantidade de pressão é transmitida através do quadril da perna mais comprida devido à diminuição na área de contato da cabeça femoral no acetábulo, assim como um aumento no tônus do quadril e abdutores secundários.

Vários mecanismos compensatórios podem ocorrer para alongar o membro menor, incluindo o aumento da obliqüidade pélvica para baixo, aumentando a extensão do joelho (COOPERSTEIN, LEW, 2009).

No teste de inclinação lateral do tronco, não houve diferença significativa entre o lado esquerdo e direito. A média ( \pm desviopadrão) para o lado direito foi de $18,0( \pm 3,75)$ e para o lado 
esquerdo 17,7 ( $\pm 2,82$ ). O teste de inclinação lateral também foi correlacionado com as medidas obtidas pela fotogrametria e mostrou apenas que, quanto maior a inclinação lateral direita, menor o desnivelamento em tragus da orelha. E quanto maior a inclinação lateral esquerda, menor o desnivelamento da espinha ilíaca póstero superior e menor será o ângulo da lordose cervical. Os estudos de Tosato e Caria relatam que o desequilíbrio dos músculos do grupo paravertebral, leva à rotação vertebral, inclinação lateral para o lado da convexidade e retificação das curvaturas fisiológicas como mecanismo compensatório (TOSATO; CARIA, 2009).

Os resultados das análises das mensurações das lordoses com a fotogrametria apontaram apenas que quanto maior a lordose cervical cefálica e a lordose cervical caudal, maior o desnivelamento no ângulo inferior da escápula. Na literatura consultada, não encontramos trabalhos que correlacionassem a profundidade das curvas (lordoses) da coluna vertebral com o método da fotogrametria, pois a mensuração das curvaturas é de difícil avaliação. Os termos como lordose normal, diminuída ou aumentada, são baseados em um contexto subjetivo, de experiências. É importante que instrumentos possam ser utilizados na prática clínica e em pesquisas, proporcionando aos fisioterapeutas uma avaliação confiável. Portanto, mais estudos ainda são necessários para aumentar o entendimento sobre o assunto.

\section{CONCLUSÃO}

A avaliação dos desvios posturais apresentados em portadores de escoliose idiopática de acordo com os métodos propostos mostrou que existe uma assimetria dos segmentos corporais envolvendo membros superiores e inferiores como consequência do desequilíbrio nas curvaturas da coluna vertebral. Quando analisadas separadamente, vimos a importância de cada avaliação, que detectam alterações posturais em indivíduos com escoliose através de métodos não invasivos e seguros. Porém, quando correlacionados com a fotogrametria, não apresentaram diferenças significativas.

\section{REFERÊNCIAS}

Carnielli, A.L; Ninello, D.A; Ferreira, D.M.A ;Pachioni, C.A.S. Análise da cifose torácica e lordose lombar em indivíduos com escoliose idiopática. Revista Eletrônica de Fisioterapia da FCT/UNESP, v.1, n.1, 2009.

Cooperstein R. MA, LEW M. The relationship between pelvic torsion and anatomical leg length inequality: a review of the literature. Journal of Chiropractic Medicine. USA, n. 8, p. 107-118. 2009 
Danielsson, A.J.; Romberg,K.; Nachemson, A.L. Spinal Range of Motion, Muscle Endurance, and Back Pain and Function at Least 20 Years After Fusion or Brace Treatment for Adolescent Idiopathic Scoliosis: A Case-Control Study. Spine, v. 31, n,3, p. 275-283, 2006. http://dx.doi.org/10.1097/01.brs.0000197652.52890.71

Faria Jr.J.C.; Barros, M.V.G.. Flexibilidade e Aptidão Física Relacionada à Saúde. Revista Corporis, v.3, n.3, 1998.

Ferreira, DMA, Defino, HLA. Avaliação quantitativa da escoliose idiopática: concordância das mensurações da gibosidade e correlações com medidas radiológicas. Revista Brasileira de Fisioterapia. v.5, n.2, p. 73-86, 2001.

Ferreira, D.M.A, Sukigawa, T.R, Pachioni, C.A.S, Fregonesi, C.E.P.T, Camargo, M.R. Rastreamento escolar da escoliose: medida para o diagnóstico precoce. Revista Brasileira de Crescimento e Desenvolvimento Humano. v. 19, n.3. p. 357-368, 2009.

Ferreira, DMA, Fernandes, CG, Camargo, MR, Pachioni, CAS, Fregonesi, CEPT, Faria, CRS. Avaliação da coluna vertebral: relação entre gibosidade e curvas sagitais por método não-invasivo. Revista Brasileira de Cineantropometria e Desempenho Humano. v. 12,n.4, p. 282-289, 2010.

Ferreira D.M.A.; Carnielli, A.L.; Ninello, D.A.; Pachioni, C.A.S.; Fregonesi, C.E.P.T., Camargo, M.R. A influência do movimento de inclinação lateral na cifose torácica e na lordose lombar de individuos com escoliose idiopática. Terapia Manual, v.8, n.38, p.325-331, 2010a.

Goldberg, C.J.; Moore, D.P. ; Kaliszer, M. ; Fogarty, E.E ; Dowling, F.E. Surface topography, Cobb angles, and cosmetic change in scoliosis. Spine, v. 26, n.4, p. E55-E63, 2001. http://dx.doi.org/10.1097/00007632-200102150-00005

Gonzalez L.J.; Sreenivasan, S.V.; Jensen, J.L. A procedure to determine equilibrium postural configurations for arbitrary locations of the feet. J Biomech Eng. n. 121, p. 644-649, 1999. http://dx.doi.org/10.1115/1.2800867

GURNEY B.,Leg length discrepancy. Gait and Posture. USA, v.15, p.195-206, april, 2001.

Pereira, O.S. A utilização da análise computadorizada como método de avaliação das alterações posturais: um estudo preliminar. Fisioterapia em Movimento, v.16, p.17-25, 2003.

Santos, L.M.; Souza, T.P.; Crescentini, M.C.V.; Poletto, P.R.; Gotfryd, A.O.; Yi, L.C. Avaliação postural por fotogrametria em pacientes com escoliose idiopática submetidos à artrodese: estudo piloto. Fisioterapia em Movimento, Curitiba, v. 25, n. 1, 2012.

Soucacos, P.N.; Soucacos, P.K.; Zacharis, K.; Beris A.E.; Xenakis, T.A. School-screening for scoliosis: a prospective epidemiological study in northwestern and central Greece. The Journal of Bone and Joint Surgery, v.79-A, n.10, p.1498-1503, 1997.

Tosato, JP, Caria, PHF. Avaliação da atividade muscular na escoliose. Revista Brasileira de Cineantropometria e Desempenho Humano. v.19, n1, p. 98-102, 2009. 
Zabjek, K.F., Leroux, M.A., Coillard, C., Rivard, C.H., Prince, F., . Evaluation of segmental postural characteristics during quiet standing in control and idiopathic scoliosis patients. Clin. Biomech. $\mathrm{n}$. 20, p. 483- 490, 2005. http://dx.doi.org/10.1016/i.clinbiomech.2005.01.003 